\title{
PERAN SELASAR SUNARYO ART SPACE SEBAGAI DAYA TARIK WISATA EDUKASI DI KOTA BANDUNG
}

\author{
Syifa Afifah Qalby ${ }^{1}$, Ute Lies Khadijah ${ }^{2}$ Awaludin Nugeraha ${ }^{2}$ \\ ${ }^{1}$ Sekolah Pascasarjana Magister Pariwisata Berkelanjutan, Universitas Padjadjaran, Jl. Dipati Ukur No. 35 \\ Lebakgade, Kecamatan Coblong, Bandung 40132 \\ E-mail: sifa.sisifa@gmail.com
}

\begin{abstract}
ABSTRAK
Galeri seni memiliki daya tarik wisata tersendiri bagi para wisatawan penikmat seni. Galeri seni memiliki arti kata ruang pameran seni yang pada umumnya diisi oleh karya berbentuk visual seperti lukisan dan patung, galeri seni juga dapat digunakan sebagai tempat untuk menjual karya seni. Salah satu tempat wisata andalan di Kota Bandung adalah wisata bangunan-bangunan bersejarah seperti museum, dan juga destinasi wisata kreatif lainnya seperti galeri seni. Galeri seni di Kota Bandung merupakan tempat objek wisata yang sering dikunjungi wisatawan, salah satunya adalah Selasar Sunaryo Art Space, sebuah ruang dan organisasi nirlaba milik seniman terkenal Indonesia yaitu Sunaryo, yang bertujuan untuk mendukung pengembangan seni dan kebudayaan visual di Indonesia. Peran Selasar Sunaryo Art Space sebagai daya tarik wisata edukasi di Kota Bandung adalah untuk memberikan peluang kepada pengunjungnya untuk terlibat langsung dengan banyak kegiatan seperti budaya, seni rupa, seni visual, dan berbagai program seni edukasi. Tidak hanya menikmati secara visual atau sambil memotret karya seni yang sedang dipamerkan, wisatawan pun dapat telibat langsung dengan kegiatan yang diadakan oleh program seni Selasar Sunaryo Art Space, contohnya seperti workshop menggambar, lokakarya tentang seni rupa, diskusi tentang buku dan film seni, talkshow, dan lain-lain. Tempat ini disebut juga sebagai tempat wisata edukasi karena melalui fasilitas exhibition guide atau pemandu pameran, wisatawan dipandu keliling ruang pameran kemudian diberikan pengetahuan tentang arti dan filosofi karya seni yang sedang dipamerkan juga diberikan pengetahuan bagaimana cara menghargai serta mengapresiasi karya seni secara baik dan benar.
\end{abstract}

Kata kunci; galeri seni, wisata edukasi, atraksi wisata.

\section{THE ROLE OF SELASAR SUNARYO ART SPACE AS AN EDUCATION ATTRACTION IN BANDUNG CITY}

\begin{abstract}
Art galleries have their own tourist attraction for art lovers. Art gallery has the meaning of the word art exhibition space which is generally filled with visual works such as paintings and sculptures, art galleries can also be used as a place to sell works of art. One of the mainstay tourist attractions in the city of Bandung is a tour of historic buildings such as museums, and also other creative tourist destinations such as art galleries. The art gallery in Bandung is a tourist attraction frequented by tourists, one of which is Selasar Sunaryo Art Space, a space and non-profit organization owned by famous Indonesian artist Sunaryo, which aims to support the development of visual arts and culture in Indonesia. The role of Selasar Sunaryo Art Space as an educational tourism attraction in the city of Bandung is to provide opportunities for visitors to be directly involved with many activities such as culture, fine arts, visual arts, and various arts education programs. Not only enjoying visually or while photographing works of art that are on display, tourists can also be directly involved with activities organized by the Selasar Sunaryo Art Space program, for example such as drawing workshops, workshops on fine arts, discussions about art books and films, talk shows, and others. This place is also referred to as an educational tourist spot because through the exhibition guide or exhibition guide facility, tourists are guided around the exhibition hall and then given knowledge about the meaning and philosophy of the art that is being exhibited as well as being given knowledge on how to appreciate and appreciate works of art properly.
\end{abstract}

Keywords: art galleries, educational tourism, tourist attractions.

\section{PENDAHULUAN}

Galeri seni atau populer dengan kata art space memiliki daya tarik wisata tersendiri bagi para wisatawan penikmat seni. Galeri seni memiliki arti kata ruang pameran seni yang pada umumnya diisi oleh karya berbentuk visual sepertakan sebagai tempat untuk menjual karya seni. Secara harfiah, istilah galeri seni adalah bangunan atau lokasi yang didedikasikan untuk menampilkan karya-karya seni rupa. Menurut Miriam Webster's Collegiete Dictionary galeri adalah sebuah trotoar untuk berjalan 
namun diatasnya terdapat atap, lalu sebuah lorong memanjang yang tidak begitu lebar yang biasa ditemui di gua, sebuah ruangan atau bangunan yang memiliki ruang cukup untuk menyimpan benda-benda seni atau hasil-hasil karya seni yang memiliki nilai sejarah dan nilai seni, atau sebuah ruangan yang dapat dipakai untuk mengadakan pameran-pameran khususnya pameran hasil-hasil karya seni yang tinggi. Kota Bandung sebagai kota yang banyak dikunjungi wisatawan setiap tahunnya memiliki berbagai macam destinasi pariwisata, dari destinasi wisata alam yang masih asri, destinasi wisata kuliner yang beragam dan terjangkau, destinasi wisata cagar budaya bangunanbangunan bersejarah seperti museum atau kawasan bersejarah yang dilindungi oleh pemerintah agar tetap dijaga keasliannya, dan juga destinasi wisata kreatif seperti galeri seni. Pertumbuhan galeri seni di Kota Bandung semakin meningkat, terlebih lagi identitas Kota Bandung sebagai salah satu kota dengan kreativitas yang tinggi membuat galeri seni semakin diminati oleh berbagai kalangan. Beberapa galeri seni yang ada di Kota Bandung diantaranya adalah Galeri Soemardja, Galeri Popo Iskandar, Galeri The Huis Dago Teahouse, Galeri Orbital, Lawangwangi Art Space, Museum dan Galeri Barli, Nu Art Sculpture Park, Omunium Space, Wot Batu, dan yang akan dibahas dalam kajian ini adalah Selasar Sunaryo Art Space sebagai salah satu daya tarik wisata edukasi di Kota Bandung.

Terletak di Jalan Bukit Pakar Timur nomor 100 Ciburial, Kecamatan Cimenyan, Kota Bandung, Selasar Sunaryo Art Space adalah sebuah ruang dan organisasi nirlaba milik seniman terkenal Indonesia yaitu Sunaryo, yang bertujuan untuk mendukung pengembangan seni dan kebudayaan visual di Indonesia. Sejarahnya secara singkat, Selasar Sunaryo Art Space diresmikan pada 5 September 1998 dengan nama Selasar Seni Sunaryo yang aktif menyelenggarakan kegiatan-kegiatan yang berorientasi pada edukasi publik terutama pada penyelenggaraan beberapa program seni rupa kontemporer, melalui pameran, diskusi, residensi, dan lokakarya. Saat itu peresmian berjalan tidak mudah, mengingat di tahun tersebut kerusuhan Orde Baru sedang terjadi, kemudian rangakaian krisis moneter dan ekonomi yang memantik demonstran di Jakarta dan beberapa kota lainnya. $\mathrm{Di}$ tengah suasana tersebut, tempat ini diresmikan dengan pameran tunggal pertamanya karya Sunaryo sendiri dengan judul Pameran "Titik Nadir" yang artinya adalah titik terendah. Dalam pameran tersebut Sunaryo memutuskan membungkus semua karyanya yang telah ia kerjakan berbulan-bulan dengan kain hitam, beberapa diantaranya lukisan dan patung, seperti sedang berkabung dengan keadaan Indonesia di tahun 1998 dan runtuhnya rezim Orde Baru, karena hal tersebut maka suasana pameran menjadi tampak murung seperti sedang berkabung (Hujatnikajennong, 2008). Tahun-tahun berikutnya Selasar Sunaryo juga menhadirkan banyak pameran seni kontemporer secara temporer dan periodik dari beberapa senimal lainnya, dan juga menampilkan seni pertunjukan seperti teater, tari, musik, monolog, pembacaan puisi dan tentunya Art Performance atau pertunjukan seni rupa. Dari peresmiannya hingga tahun 2002 Selasar Sunaryo Art Space menyelesaikan sejumlah renovasi serta mengembangkan dan menambahkan beberapa fasilitas tambahan untuk mendukung Pameran Seni Rupa.

Sejumlah pameran skala besar dan pertunjukan seni telah dilaksanakan. Sebagai pusat kebudayaan, Selasar Sunaryo Art Space telah menyelenggarakan kegiatan-kegiatan yang berhubungan dengan disiplindisiplin seni lain seperti desain, kriya, seni pertunjukan, sastra, arsitektur, dan lain sebagainya. Selain memajang koleksi permanen, Selasar Sunaryo Art Space juga menyelenggarakan pameran-pameran tunggal atau bersama yang menampilkan karya-karya para seniman muda dan senior, dari Indonesia maupun mancanegara. Semua jenis kegiatan di tempat ini mencakup program anak-anak, konser musik, pementasan tetaer, pemutaran film, pembacaan karya sastra, ceramah dan berbagai aktivitas lainnya dirancang berdasarkan arahan dari Dewan Pertimbangan Kuratorial yang terdiri dari para akademisi, kritikus dan praktisi seni. Selasar Sunaryo Art Space juga berkiprah dalam jejaring seni rupa kontemporer internasional melalui kerjasama dengan berbagai insitusi di luar negeri.

Penulisan ini bertujuan untuk mendeskripsikan bagaimana Selasar Sunaryo Art Space menjadi salah satu daya tarik wisata di Kota Bandung yang menjadi media juga tempat untuk memberikan edukasi kepada wisatawan. Sesuai dengan misi dari Selasar Sunaryo Art Space yaitu; (1) untuk mendukung pengembangan seni dan budaya, juga pengembangan infrastruktur budaya berkelanjutan di Indonesia, kemudian (2) untuk memberikan peluang kepada masyarakat umum untuk terlibat langsung dengan kegian budaya, seni visual, dan program seni pendidikan atau edukasi, kemudian (3) untuk menjadi pusat sumber daya dan menawarkan akses ke informasi tentang seni rupa Indonesia juga internasional, dan yang terakhir adalah (4) untuk menampung dan mempelajari karya seni Sunaryo sebagai salah satu tokoh terkemuka dalam perkembangan seni Indonesia.

\section{METODE}

Metode yang digunakan dalam penulisan penelitian ini adalah deskriptif kualitatif. Adapun tujuan dari penelitian ini dengan metode deskriptif kualitatif adalah untuk mengungkapkan kejadian atau fakta, keadaan, fenomena, variabel dan keadaan yang terjadi saat penelitian berlangsung dengan menyuguhkan apa yang sebenarnya terjadi. Penelitian ini menafsirkan dan menguraikan data yang bersangkutan dengan situasi yang sedang terjadi, sikap serta pandangan yang terjadi di dalam suatu masyarakat, pertentangan antara dua keadaan atau lebih, hubungan antar 
variable yang timbul, perbedaan antar fakta yang ada serta pengaruhnya terhadap suatu kondisi, dan sebagainya. Metode deskriptif kualitatif dalam penelitian ini adalah untuk menggambarkan bagaimana keadaan Selasar Sunaryo Art Space yang berada di Kota Bandung sebagai daya tarik wisata yang berperan dalam wisata edukasi.

\section{HASIL DAN PEMBAHASAN}

Seperti yang diketahui wisata edukasi menjadi salah satu wisata yang banyak diminati oleh wisatawan berbagai kalangan, dari anak-anak, kalangan muda, hingga kalangan dewasa. Wisata edukasi menjadi hal yang penting bagi perkembangan pariwisata di Kota Bandung, karena edukasi atau pendidikan dan pariwisata merupakan dua hal yang berbeda namun keduanya dapat saling melengkapi. Proses pendidikan yang dilakukan dalam aktivitas wisata merupakan sebuah alternatif metode pembelajaran yang efektif. Pengertian singkat tentang wisata edukasi adalah upaya meningkatkan pengetahuan baru melalui kegiatan wisata (Pevzner \& Nikoleva dalam Hermawan, 2018). Contoh tempat-tempat yang biasanya dikategorikan menjadi tempat wisata edukasi adalah museum, cagar budaya, bangunan bersejarah, kebun binatang, pusat pengetahuan alam, dan galeri seni atau art space.

Berhubungan dengan hal tersebut Selasar Sunaryo Art Space menjadi tempat yang termasuk ke dalam kategori tempat wisata edukasi di Kota Bandung, karena sesuai dengan misi dari tenpat ini yaitu untuk memberikan peluang kepada masyarakat umum untuk terlibat langsung dengan kegian budaya, seni visual, dan program seni pendidikan atau edukasi. Alasan lainnya adalah karena fasilitas yang dimiliki oleh Selasar Sunaryo Art Space cukup menunjang untuk para wisatawan yang mencari tempat wisata edukasi di Kota Bandung. Fasilitas yang tersedia di Selasar Sunaryo Art Space diantaranya, Ruang Pamer yang terdiri dari Ruang A, Ruang B, Ruang Sayap, dan Bale Tonggoh, ruangan-ruangan tersebut adalah ruangan yang digunakan untuk memajang karya seni. Kemudian Amphiteater atau area pertunjukan, area ini biasanya digunakan untuk pertunjukan seni teater, musik, pembacaan puisi, pembacaan monolog, dan pertujukan seni tari. Kemudian Bale Handap, area ini biasanya digunakan untuk tempat acara talkshow, seminar, workshop, lokakarya, diskusi pembahasan buku atau film, dan acara-acara formal lainnya. Kemudian Rumah Bambu, area ini adalah rumah yang digunakan untuk menjamu para seniman dari berbagai kota yang sedang melakukan kegiatan residensi untuk seniman. Kemudian ada Taman Batu, taman ini teletak di sebelah ruang pamer utama dan berfungsi sebagai tempat dipajangnya karya permanen Sunaryo yang terdiri dari beberapa elemen batu, tempat ini juga menampilkan nilai estetika sebuah ruang terbuka. Lalu ada Pustaka Selasar, tempat ini adalah perpustakaan yang memiliki koleksi buku sekitar 1500 tentang seni rupa, fotografi, katalog pameran, arsip lengkap tentang Selasar Sunaryo Art Space, buku teater dan juga sastra, monograf, majalah, jurnal cetak berbentuk kliping, poster, makalah, dan transkrip diskusi wawancara dengan para seniman. Kemudian Cinderamata Selasar atau toko cinderamata Selasar Sunaryo Art Space, toko ini menyediakan berbagai koleksi para seniman termasuk koleksi Selasar Sunaryo Art Space sendiri berupa tas, buku, buku catatan, baju, katalog, alat lukis, dompet, jam tangan, syal, anting, poster, gantungan kunci, dan masih banyak lagi barang lainnya. Kemudian Kopi Selasar, area ini adalah tempat restauran dan dudukduduk santai sambil menikmati kopi ciri khas Selasar Sunaryo Art Space yang dibuat dari kopi dengan tambahan jahe dan susu, makanan ringan maupun makanan berat seperti Chinesse Food, Western Food, dan Indonesian Food juga tersedia di Kopi Selasar. Selain itu fasilitas amenitas seperti toilet, mushola, pos keamanan, dan tempat parkir kendaraan juga tersedia di tempat ini. Berikut foto-foto area yang berada di Selasar Sunaryo Art Space.

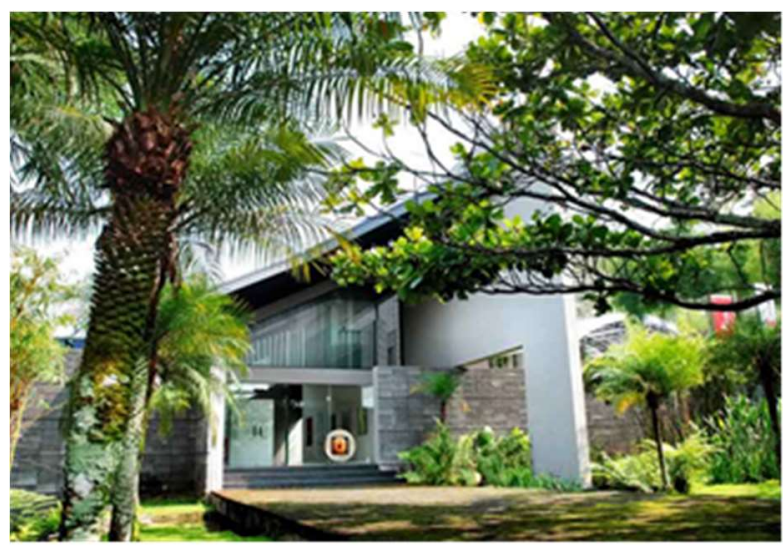

Gambar 1. Ruang Pamer Utama Selasar Sunaryo Art Space Sumber: (http://www.selasarsunaryo.com/ diakses pada Minggu, 10 November 2019, pukul 15.43).

Selain fasilitas yang lengkap, pameran-pameran karya seni rupa yang diadakan oleh Selasar Sunaryo Art Space sangat beragam dan menarik, seniman dari berbagai gaya kontemporer yang masih muda maupun yang sudah terkenal bekali-kali menggunakan ruang pamer Selasar Sunaryo sebagai tempat menampilkan karya seni mereka. Tidak tekecuali bagi Sunaryo sendiri, setelah sukses mengadakan pameran Satu Dekade Selasar Sunaryo di tahun 2008 silam sebagai pameran untuk memperingati 10 tahun Selasar Sunaryo Art Space, di tahun 2018 pameran memperingati 20 tahun Selasar Sunaryo Art Space pun diadakan. Pameran tersebut berjudul "Lawangkala: Memperingati 20 Tahun Selasar Sunaryo Art Space", diadakan pada bulan September hingga bulan Desember tahun 2018.

Pameran Lawangkala ini sangat diminati oleh berbagai kalangan, dari para seniman, penikmat seni, ataupun wisatawan mancanegara, pameran ini juga meningkatkan jumlah wisatawan yang berkunjung ke 
Selasar Sunaryo Art Space dan akhirnya di perpanjang hingga bulan Juni 2019 lalu. Pameran Lawangkala ini hanya menampilkan semua karya seni yang dibuat oleh Sunaryo di semua ruang pamer. Lawangkala sendiri memiliki filosofi yang mendalam, Lawangkala adalah istilah campuran, lawang atau pintu sebagai arsitektur dengan konotasi fisik dan kala atau waktu disini dibayangkan sebagai objek yang menyatu dengan lawang, pintu atau gerbang, maka Lawangkala juga berarti dimensi campuran, dimana ruang dan waktu menjadi satu. Sunaryo juga memiliki keinginan luar biasa untuk bekerja dengan ruang, baik terbuka maupun tertutup, sempit dan lebar, publik dan pribadi, alam atau industri, dan sebagainya, bagi Sunaryo ruang adalah medium dan material tersendiri. Sunaryo mendesain instalasi ini sedemikian rupa sehingga para pengunjung Selasar Sunaryo Art Space mengalami rasa dari ruang dan waktu secara bersamaan. Pengunjung akan berjalan di setiap belokan terowongan bambu yang berderak, pengunjung akan merasakan instalasi seni di ruang dan waktu yang "lain".

Ada linearitas yang kuat di Lawangkala yang secara halus menyiratkan sudut pandang Sunaryo tentang konsep ruang dan waktu misalnya, dalam ruang dan waktu yang akan kita alami, tidak pernah ada "rute dan gerak" yang lurus, dan di dalam diri kita akan dihadapkan dengan "jebakan" di mana kita harus memilih dan memutuskan berdiri atau tinggal, terpaku pada ilusi aliran air, atau bergerak untuk melanjutkan "perjalanan". Instalasi ini sebanding dengan lensa mikroskopis yang meneliti fragmen atau momen terkecil dalam kehidupan manusia. Untuk menjelajahi karya seni instalasi ini wisatawan dibantu oleh exhibition guide atau pemandu pameran yang menjelaskan setiap bagian ruang dari pintu utama Lawangkala hingga pintu keluarnya. Sebagai tempat wisata edukasi, Selasar Sunaryo Art Space telah memberikan pelayanan terbaik untuk para wisatawan yang berkunjung, selain beberapa fasilitas ruang yang sangat memadai, fasilitas pemandu pameran juga menjadi elemen yang sangat penting untuk menjadi daya tarik destinasi ini. Tugas dari pemandu pameran ini selain membantu memandu dan mejelaskan karya mereka pun bertugas untuk memberikan pengetahuan seni rupa dasar dan juga bagaimana pentingnya menjaga suatu karya seni yang sedang dipamerkan. Para pemandu pameran ini memberikan pengarahan tentang peraturan yang boleh dan tidak boleh dilakukan selama mengunjungi pameran, seperti peraturan dasar dalam menghargai karya seni diantaranya tidak boleh menyentuh karya seni, para pemandu pameran ini selain melarang juga menjelaskan alasan dari peraturan ini. Contoh peraturan dasar lainnya adalah dilarang memotret karya menggunakan lampu kilat kamera, alasannya adalah daya kilat sebuah lampu kilat dapat memudarkan warna karya dan lama-kelamaan akan merubah warnanya. Contoh lainnya yaitu peraturan untuk mohon menjaga jagar agar tidak terlalu dekat dengan karya seni dan juga tidak memotret karya seni terlalu dekat karena secara tidak sengaja dapat menyenggol karya seni yang sedang dipamerkan. Lalu peraturan dasar lainnya yaitu tidak membawa makanan dan minuman ke dalam ruang pamer karena selain dapat mengotori ruang pamer juga dapat mengenai karya seni secara tidak sengaja (Viciana, 2019). Peraturan-peraturan dasar ini menjadi alasan mengapa Selasar Sunaryo Art Space menjadi tempat yang cocok disebut sebagai tempat wisata edukasi di Kota Bandung karena tempat ini mengedukasi para wisatawannya tentang bagaimana menghargai suatu karya seni.

\section{SIMPULAN}

Wisata edukasi di Kota Bandung memang sangat populer, yang paling diminati adalah wisata museum, gedung bersejarah, cagar budaya, dan galeri seni atau art space. Selasar Sunaryo Art Space adalah tempat yang cocok disebut sebagai tempat wisata edukasi selain fasilitas yang lengkap dan menunjang untuk kegiatan seni rupa, tempat ini juga memberikan peluang kepada pengunjungnya untuk terlibat langsung dengan banyak kegiatan seperti budaya, seni rupa, seni visual, dan berbagai program seni edukasi. Tidak hanya menikmati secara visual atau sambil memotret karya seni yang sedang dipamerkan, wisatawan pun dapat telibat langsung dengan kegiatan yang diadakan oleh program seni Selasar Sunaryo Art Space, contohnya seperti workshop menggambar, lokakarya tentang seni rupa, diskusi tentang buku dan film seni, talkshow tentang pembukaan pameran seni oleh seniman yang memamerkan karyanya di ruang pamer Selasar Sunaryo Art Space, dan masih banyak kegiatan lainnya. Wisatawan dapat menikmati berbagai pertunjukan teater, konser musik, pembacaan puisi di Amphiteater atau hanya sekedar duduk manis menikmati kopi, cemilan, dan makanan di Kopi Selasar. Tempat ini disebut sebagai tempat wisata edukasi karena tempat ini berperan sebagai tempat mengenalkan wisata edukasi melalui fasilitas exhibition guide atau pemandu pameran, wisatawan dipandu keliling ruang pameran kemudian diberikan pengetahuan tentang arti dan filosofi karya seni yang sedang dipamerkan juga diberikan pengetahuan bagaimana cara menghargai serta mengapresiasi karya seni secara baik dan benar. Maka setelah wisatawan selesai berkunjung ke Selasar Sunaryo Art Space tidak hanya membawa pulang koleksi foto di galeri handphone mereka tetapi juga membawa pengalaman seni dan pengetahuan baru tentang suatu karya seni. 


\section{DAFTAR PUSTAKA}

Pustaka yang berupa majalah/jurnal ilmiah:

Elvina, R. Nina. (2006). Selasar Sunaryo Art Space dan Potensinya sebagai Salah Satu Daya Tarik Wisata di Kota Bandung. Bandung: STBA Yappari..

Hermawan, Hary. (2018). Upaya Mewujudkan Wisata Edukasi di Kampung Tulip Bandung. Saepudin, E. (2016b). JURNAL ABDIMAS BSI Jurnal Pengabdian Kepada Masyarakat. Retrieved from https://ejournal.bsi.ac.id/ejurnal/index.php/abdimas/ article.com
Pustaka yang berupa judul buku:

Hujatnikajennong, Agung. (2008). Dedikasi Satu Dekade. Bandung:Yayasan Selasar Sunaryo..

Siregar, Aminuddin T.H. (2007). Instalasi Sunaryo (19982003) Bandung: Yayasan Selasar Sunaryo.

Pustaka yang berupa wawancara:

Viciana, Pradini. (November, 2019). Tugas Exhubition

Guide di Selasar Sunaryo Art Space. Bandung. 